University of Louisville

ThinkIR: The University of Louisville's Institutional Repository

Electronic Theses and Dissertations

$5-2007$

\title{
Violence and horror : the anti-technology of subjectivity.
}

Christopher William Curry 1973-

University of Louisville

Follow this and additional works at: https://ir.library.louisville.edu/etd

\section{Recommended Citation}

Curry, Christopher William 1973-, "Violence and horror : the anti-technology of subjectivity." (2007). Electronic Theses and Dissertations. Paper 304.

https://doi.org/10.18297/etd/304

This Master's Thesis is brought to you for free and open access by ThinkIR: The University of Louisville's Institutional Repository. It has been accepted for inclusion in Electronic Theses and Dissertations by an authorized administrator of ThinkIR: The University of Louisville's Institutional Repository. This title appears here courtesy of the author, who has retained all other copyrights. For more information, please contact thinkir@louisville.edu. 
VIOLENCE AND HORROR: THE ANTI-TECHNOLOGY OF SUBJECTIVITY

$$
\text { By }
$$

Christopher William Curry

B.A., University of Louisville, 2005

\author{
A Thesis \\ Submitted to the Faculty of the \\ Graduate School of the University of Louisville \\ In Partial Fulfillment of the Requirements \\ For the Degree of
}

Master of Arts

Department of English

University of Louisville

Louisville, Kentucky

May 2007 
VIOLENCE AND HORROR: THE ANTI-TECHNOLOGY OF SUBJECTIVITY

\author{
By
}

Christopher William Curry

B.A., University of Louisville, 2005

A Thesis Approved on

April 6, 2007

by the following Thesis Committee:

Thesis Director 


\section{DEDICATION}

This thesis is dedicated to my sons, Evan and Jackson, for giving me the inspiration I need in order to succeed. 


\section{ABSTRACT \\ VIOLENCE AND HORROR: THE ANTI-TECHNOLOGY OF SUBJECTIVITY Christopher W. Curry \\ March 25, 2007}

This thesis is about graphic representations of violence and subjectivity. Simply stated, the violence in many recent horror films is motivated by a nihilism resulting from frustration with the inadequacy of contemporary subjectivity. I want to explore the potential such representations have for providing a means of radically undermining the contemporary category of subjectivity. This subversion is due to what I call the inverted mirror stage effect in combination with a particular dislocation of the audience that is associated with the spectacle of violence displayed in contemporary, or postmodern, horror films. My theoretical approach is a cultural materialist psychoanalytic one that facilitates the traversal of the gap between individual and society by focusing attention not merely on society as a product of individuals, or vice versa, but instead upon the dynamic interaction of the two. Also, this essay draws upon the work of several feminist film theorists, including Carol J. Clover, Judith Halberstam, and Laura Mulvey. 


\section{ACKNOWLEDGMENTS}

I would like to thank my thesis director, Dr. Matthew Biberman, for his patience and insight in working with me on this project. Without his guidance I doubt I would have been able to develop this thesis from an initial vague idea into a finished product of intellectual inquiry. Likewise I want to thank Dr. Aaron Jaffe for his continuous encouragement and support, and also Dr. Osborne Wiggins for agreeing to be a part of this project. Also I must thank all the professors who have had a major impact upon my intellectual development: Dr. Beth Willey, Dr. Karen Hadley, Dr. Dennis Hall, Dr. Carol Mattingly, and Dr. Bronwyn Williams of the English Department, Dr. D. A. Masolo, Dr. Robert Kimball, and Dr. Eileen John of the Philosophy Department, and finally Dr. Allen Share and Dr. Michael Williams of the Humanities Department. And thank you to my family for all their love and support. 
TABLE OF CONTENTS

PAGE

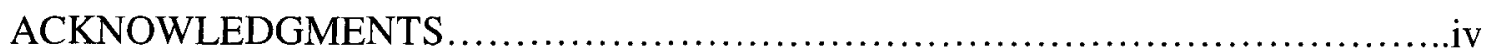

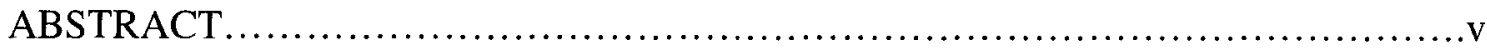

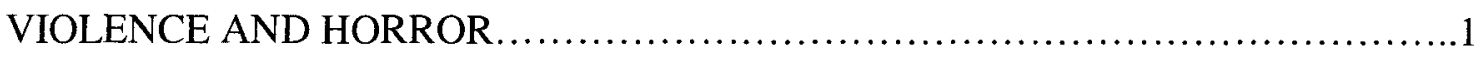

THE SUTURE AND ABYSS ...................................................... 17

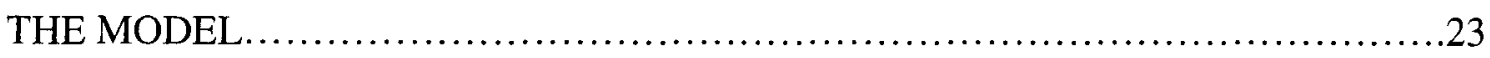

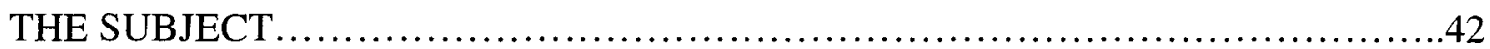

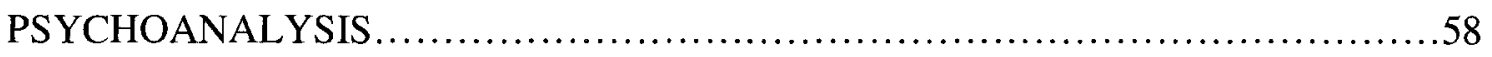

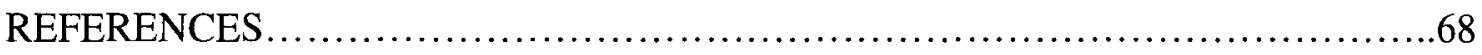

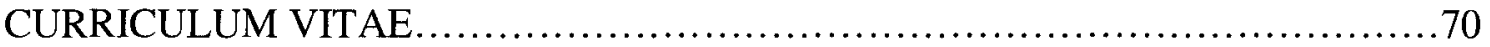


"For this consciousness was not in peril and fear for this element or that, nor for this or that moment of time, it was afraid for its entire being; it felt the fear of death, the sovereign master. It has been in that experience melted to its inmost soul, has trembled throughout its every fibre, and all that was fixed and steadfast has quaked within it. This complete perturbation of its entire substance, this absolute dissolution of all its stability into fluent continuity, is, however, the simple ultimate nature of self-consciousness, absolute negativity..." GWF Hegel, The Phenomenology of Mind (237).

\section{VIOLENCE AND HORROR}

There is a basic relationship of violence and horror. Whether violence is real, that is to say it takes place, that violence actually happens, that the peril of violence is realized, or whether merely the threat of violence exists, the peril of potential violence, one or the other of these situations does not make a difference when it comes to ascribing violence as the central motivating force in a horror film. It is important to distinguish between fear and horror. Fear, the sensation that is most associated with horror films, is actually rather non-essential to the experience of a horror film. In fact, the fear-provoking 
elements of horror films often have little to do with the violence in these films, other than the rather obvious fear that some may viewers may experience as a vicarious reaction to on-screen deaths, an expression of the viewers' more or less conscious "fear" of death ${ }^{1}$. Fear is often the result of viewers estrangement within the fictional world of the horror film, a feeling not dissimilar to (but not entirely identical with) Freud's famous explanation of unheimlich, the uncanny. Suspense, uncertainty, the sense that although things seem normal they are in fact not, the feeling that there is something lurking beneath or behind the otherwise genteel exteriors of normal experience that is somehow menacing, these are fear-provoking elements common in horror films. Their relation to the uncanny is clear enough, but they are not enough to make horror. Horror is physical, it is bodily. The word has roots in a physical description, the Latin horrer meaning "bristling." I don't want to push the etymology too much but its worth mentioning that fear appears to be psychological in nature while horror is physical; fear happens in the mind, an intellectual response, while horror is of the body, in the body, and, as it were, can be found in opening up the body.

Strip away all the generic conventions of horror and there is an identifiable situation that is basic, one that can be described as follows: a subject is in peril of violence. Horror is always about the peril of violence upon a subject, violence that is either real - the peril realized - or potential - the peril postponed. Horror films can be characterized as either the pursuit of the realization of this potential violence, a threat in pursuit of a victim or victims, or as the realization of this potential, a threat executing

\footnotetext{
${ }^{1}$ Compare with the Freudian theory of the joke in The Joke and its Relation to the Unconscious.
} 
violence upon a victim or victims. How many horror films do not fit this formula? Are there any? The horror genre is privileged in this essay. Violence plays a role in other aesthetic genres, certainly, but violence is not fundamental to any other contemporary aesthetic genre in the same way it is for horror.

Another reason is the radical nature of horror films. The radical progressive potential of horror films has long been recognized, at least from Robin Wood's seminal 1979 essay "An Introduction to the American Horror Film." Wood argues that horror films need to be understood politically and as social critique-"I have stressed," he writes, "the genre's progressive or radical elements, its potential for the subversion of bourgeois patriarchal norms" (192). One such potential for subversion is the very topic of this essay, the subversion of modern subjectivity ${ }^{2}$. Wood goes on to distinguish between "the reactionary horror film," in which progressive ideas are diminished or entirely absent (Wood's primary example is Halloween), and what he calls "the 'apocalyptic' horror film":

The latter expresses, obviously, despair and negativity, yet its very negation can be claimed as progressive: the "apocalypse," even when presented in metaphysical terms (the end of the world), is generally reinterpretable in social/political ones (the end of the highly specific world of patriarchal capitalism). The majority of the most distinguished American horror films (especially in the 70's) are concerned with this particular apocalypse; they are progressive in so far as their negativity is not recuperable into the dominant ideology, but constitutes (on the contrary) the recognition of that ideology's disintegration, its untenability, as all it has repressed explodes and blows it apart. (192)

\footnotetext{
${ }^{2}$ See Lacan's "The Subversion of the Subject and The Dialectic of Desire in the Freudian Unconscious."
} 
In Wood's formulation the potential for positive change found in horror film begins with its "negative capability," 3 that is to say its ability to negate, subvert, and undermine. In this manner horror functions less as a socio-cultural corrective than as a means of clearing away space in which other forms of socio-cultural constructs (which is purposefully not to say "better" or "worse" forms) can come into being. It is this radical progressive potential and the intrinsic relationship of the genre and violence that accounts for the focus on horror films.

If violence is essential, then the horror film can then be understood, in a sense, as a staging of this essential violence, as a means of representing violence. Since film is inevitably a medium of visual representation it is therefore essentially of interest to examine the manner in which violence has been visually represented in horror films. Only through an analysis of the visual elements can horror films be read in relation to Wood's claim. Consider, for instance, the difference in representation of violence in two horror films from two different eras: Alfred Hitchcock's Psycho (1960) and Eli Roth's Hostel (2005).

Both films are about the horror that befalls more or less innocent victims while staying in rented places of lodging, and thus share an immediate thematic connection. Furthermore, both films are concerned with psychic economies of sex and violence. Norman Bates cannot resist being overwhelmed by the need to commit violence whenever his libido is aroused; an increase in his sexual energy results in a homicidal surge of violence. Moreover, it is significant that his violence expresses itself in explicitly

\footnotetext{
${ }^{3}$ Not Keats' concept but the Marxist version associated with the Frankfurt School.
} 
sexual terms, the stabbing of a naked female body is very much a perverse analogy to the sex act that he desires but cannot enact. Hitchcock's film is essentially reactionary, dogmatic, and self-loathing — the drive of the film seems to be one of establishing patriarchal authority but in doing so masculinity becomes contaminated with a perverse feminine sexuality. In Hostel both sex and violence are explicitly described as types of commodified pleasures, more or less equal (though at least one character specifically claims to enjoy the pleasure of violence more than the pleasure of sex), and both available for a price. Hostel is very much concerned with demonstrating the basic dehumanization inherent in utilitarian-inspired capitalist thinking: pleasure is (a) good, pleasure can be bought and sold, pleasure is an end, the ultimate end, in itself. Questions regarding the nature of pleasure, about its costs (in an extra-fiduciary sense, as in cost of human lives), are irrelevant. Finally, the Bates Motel and the Slovakian hostel are especially terrifying due to the breach of social code that takes place within their walls: the victims have paid for safety, instead they have purchased their doom. All manner of basic assumptions about civil society are upset by the situations in these two films, but what I want to limit my focus to is the manner in which the horror, which is to say the violence, that occurs in these two films is depicted.

Psycho, released in 1960, "changed the way Americans understood horror," according to Kendall R. Phillip (64). It was in Psycho that the horror hid itself under a blanket of banality, or so goes the standard reading of the film. In fact, instead of decentering the genre of horror by remaking the monster as the boy next door, the film actually reinforces the standard, or what I'll refer to as the modern, model of horror-the 
horror ex-sists in an otherwise normal world, it comes from outside, it is an aberration. I will return to this point. For now it suffices to say that Psycho is for me the pre-eminent cinematic example of modern horror.

The shower scene is perhaps the single most well known cinematic death in history, "the most famous sequence in the history of American cinema" (Phillips 63). Many people know the scene without actually having seen the entire film. It is a cultural icon. Homages to, not to say outright thefts from, the scene abound in subsequent films, ranging from comical parodies (Mel Brooks' High Anxiety) to deadly serious reinterpretations (DePalma's Dressed to Kill). One merely has to invoke the staccato violin stabs of Bernard Herrman's equally iconic score in order to bring disturbing images of brutal murder to mind. But in examining the scene itself one might be surprised, especially if one has seen a film such as Hostel, at how little actual violence is shown.

Certainly the scene is violent: a woman is brutally stabbed to death. But the violence is not represented in a manner which seems particularly violent in comparison to a film like Hostel. There are no close-ups of Norman's knife piercing Marian's flesh, no shots of wounds spurting blood, in fact there are no shots in which the audience sees Norman (in full frame) stab Marian (also in full frame simultaneously) at all. The knife is raised, it falls, there is the sound effect of blade into body (a total of eight), Marian screams and fights. There is, very briefly (lasting less than a second when the film is played at half speed), the image of the knife's tip drawing a bit of blood right beneath Marian's belly button; this single moment of contact between steel and flesh is followed 
by Marian's cry "Oh!" There is blood, yes, but very little. What is most striking about this image is the undisguised conflation of sexual mutilation, sexual pleasure, and the male gaze upon the vulnerable female subject. The next knife blow, apparently landing in Marian's heart, is followed by the first shot of the bottom of the bathtub where blood spatters and drips (as is well-known, chocolate syrup was used for the blood). Marian turns and is stabbed once more, then falls. Norman flees. The camera settles upon Marian, slumped in the tub and breathing hard. She tries to pull herself up with the shower curtain but it breaks loose and she falls into the bathroom floor, halfway out of the tub. Another tracking shot follows, probably the film's most famous one, in which the water swirls down into the dark of the shower drain, the shot dissolving into a darkness that becomes Marian's pupil in the next shot. The entire scene lasts barely a minute, with the actual violence of the attack contained in half that amount of time. The most famous murder in cinema is over very quickly. The violence in $P$ sycho is rapid, largely implied, and ends in death.

\section{Not so in Hostel.}

Violence in Hostel is slow, laborious, very explicit, and is, in and of itself, totally unrelated to death. Violence in Hostel is not about murder, although it is a rather safe bet most of the victims of violence end up dead. It is worth pointing out thought that those characters who are simply murdered in the film, as opposed to submitted to torture, all die (more or less) quickly. Murder happens, but it is not usually subject to the same 
spectacle that violence is in this film ${ }^{4}$. Hostel's plot concerns an agency located in Slovakia that provides human victims to high paying clients who, in the confines of a dungeon-like abattoir, can then do what they please with them. The film can be read in various ways, but in my view it is primarily a critique of global capitalism, conflating as it does the exploitative capitalist mentality with a need for violence.

What makes Hostel different from Psycho, and this is, generally speaking, the difference between classic (or modern) horror films and contemporary (or postmodern) horror films is the manner in which the violence is represented, both in terms of visual representation and in terms of motive. The violence is its own purpose. The pleasure of violence, exulting in savoring violence, violence as a visual pleasure-these are the concerns of the postmodern horror film with violence. What happens to Marian is necessary for the logic of the fictional world ${ }^{5}$ in which Psycho takes place (there must be some transgression of the normal in order to identify an aberration—it is the aberration that is "psycho"); it is equally necessary for the narrative logic of the film (something has to happen to Marian). The violence is a consequence of the murder, the latter which is necessary for both the logic of the film's fictional world and the narrative.

The violence in Hostel isn't necessary for the logic of its fictional world; it is a consequence. As for its relation to the narrative, it will become apparent from what follows that the violence has no place, properly speaking, within the film's narrative.

\footnotetext{
${ }^{4}$ Paxton shoots a number of people once he escapes; they all die perfunctorily. He also drives a car over some other people. The only murder that takes on some aspect of the rest of the violence of the film, and this is surely intentional, is Paxton's final confrontation with the Surgeon. It is significant that the previous murders were all carried out at a distance (a gun, from inside a car), while the last killing takes place with a razor blade in very close quarters.

5 The logic of the film's fictional world, which I'll later refer to as the ontology of the fictional world, will become significant as this discussion proceeds. See Section Three, The Model p. 25.
} 
Instead, the narrative derives from the need to display violence. What happens to Josh isn't about violence taking place in a narrative. It is about the spectacle of violence. It is about torture ${ }^{6}$.

Elaine Scarry, in her landmark study of torture The Body in Pain, claims that one cross-cultural constant in torture is the elevation of the instruments into an aspect of the process. She describes this taking place through the visual display of the instruments, allowing the victim to acquire visual familiarity with the instruments of torture before the torture takes place. For Scarry the torture is already taking place in this visual display; the display is as much a part of the torture as is the use.

Roth constructs the scene of Josh's torture in such a manner as to emphasize the implements, to draw attention to the equipment of this filthy business. There are several close ups of dirty table tops strewn with grimy hand tools, odd angled pieces of metal, needle nose pliers, rusty implements of all sorts, and one heavy duty high powered drill with a mean looking foot long $1 / 4$ inch bit. Josh's position as spectator is limited at first due to the hood he wakes up wearing. The first shots of the scene are from within this mask: the audience looking through one ragged edge hole, hearing Josh's up close heavy breathing and muttered cries. But once the Surgeon has entered, exposed himself as the ultimate implement, the guiding will of torture, off comes the hood and Josh (along with the audience) gets a full view of the dungeon abattoir. Of course, this is when Josh's pleading begins in earnest. During this sequence of crying and begging for mercy the

\footnotetext{
${ }^{6}$ The cinematic image of violence in recent horror films is often one of torture-in fact, several film critics, such as New York Magazine's David Edelstein, have labeled the new horror genre as "torture porn," citing films like The Devil's Rejects, Saw, Wolf Creek and even Mel Gibson's controversial The Passion of the Christ, as examples ("Torture Porn").
} 
audience perspective shifts to that of the Surgeon as he examines the instruments at hand-this is when the sweeping shot of the table littered with tools takes place. This is the last time in the scene that perspective is so fully accommodated by one of the characters. After this point the audience vantage point is somewhat like a third person limited narrator: taking in the action from neither character's direct point of view but not having total access to what's happening either. For instance, although the piercing of Josh's thigh with the drill is shown in extreme close-up it is not clear from which character's perspective, if either, the audience is seeing it. Also, when the Surgeon unbinds Josh and tells him he's free to go, after opening up the door, the camera angle is such that the audience cannot see-until Josh has already tried to stand, which is to say until its too late-that the Surgeon has used his scalpel to slash Josh's Achilles tendons while un-cuffing him. The audience experiences this horror, that the offer of escape was just another cruelty, just as Josh experiences the pain of his legs breaking off from his feet, pitching him helplessly to the floor.

This is another way in which this scene draws upon Scarry's description of torture: she claims that by making the scene of torture, the very situation of the torturer and the tortured, so much a part of the torture process, then the "unmaking" effect of torture is heightened. One way of doing this is to hold out the offer of freedom without ever intending to follow up on it. The tortured person is made aware of the limits of their body, the absurdity of their body's position in the space of torture, the frailty of their body under the pressures of torture, and it is this awareness that is integral to their unmaking. It is significant just how much the tortured person's concept of their own body 
comes into play in the unmaking effect of torture; as will be more fully explained, it is exactly this self-conception as a body that is at stake in the subjectivity-disintegrating effect of violence in contemporary horror films.

What makes the scene of Josh's torture distinct from the shower scene is the difference in purpose. Hitchcock filmed a death scene, calculating its effect in a narrative scheme and with the logic of his fictional world dictating his choices. Marian's murder was a major turning point in the story and was necessary in order to demonstrate the aberrant "psycho" run amok in an otherwise "normal" world. In Hostel death is not the purpose of the violence, it is not the proverbial payoff. In fact, the audience never even sees Josh's death (unlike other contemporary horror films Hostel never actually shows anyone tortured to death). The violence is its own purpose, it is violence for its own sake, it is violence so that the audience can experience the spectacle of violence. The Surgeon commits the violence in order to experience for himself the pleasure of torture-a pleasure, one should not forget, that is not only bought but that is also explicitly linked with sexual pleasure. For instance, while the Americans are still in Amsterdam there is a scene in which Josh wanders down an ultraviolet-lit brothel hallway, passing translucent doors through which he can see (and hear) the sounds of commodified sexual pleasure; later, in the Slovakian abattoir, that scene is mirrored when Paxton is captured and dragged down the hallway, passing several open doors through which he can see (it is significant these doors are open: he can see the violence) several scenes of gruesome torture. It is at the end of this latter scene that the audience sees (with Paxton), for the first time, Josh's corpse, chest cavity splayed open, now in the process of being operated 
on by the Surgeon. Death, it seems, is merely an afterthought, something that happens as a result but not as the only intended result. The relationship of sex and violence in Hostel could be stated in these terms: like sex, violence takes place as an activity with its end in the experience of the act, not the outcome. But, and any serious analysis must not lose sight of this obvious fact, the Surgeon doesn't just commit the violence for his own pleasure, for the pleasure of his own experience. He also commits violence so that the audience can experience it too.

The violence of the torture is its own end, its own purpose. It is less about narrative necessity and more about displaying the spectacle of violence enacted upon the body. This is characteristic of contemporary, or postmodern, horror films. How does one explain this difference from classic, or modern, horror films? Its not the case that audience preferences have simply grown more sadistic in recent years; in fact, according to Carol Clover, in her hugely influential study of horror films Men, Women and Chainsaws, through identification audiences experience horror films not as detached third person viewers (which would be a necessary condition for sadistic voyeurism to be an issue) but instead more personally, more intimately. Fascinated by the flickering images on the screen, the audience identifies with what they see, what they see becomes, in a sense, a part of what they are. Identification is basic to the frightening effects of a horror film: if it were not for an audience placing themselves in the peril they witness on screen there would be no fear, no horror. In other words, it is via audience identification that the 
fear effects of horror are possible: the audience experiences the film as if they were a part of the film, as if they were the victims ${ }^{7}$, and, as Clover argued, as the victimizers.

It seems to me that the lasting effect of a horror film, in terms of identification, would derive from the manner in which the audience related to the narrative in which the violence took place, that is to say the narrative of the film. The relationship of audience to horror film narrative has changed dramatically from the modern to postmodern era, and this is due to a shift in ontology of the films' fictional worlds. This point will be explained more fully. Ultimately the film's narrative imposes some limit upon identification, or at least orders things in such a way as to emphasize identification with one figure or another. This is why the violence of contemporary horror films seems especially problematic.

As Hostel demonstrates the violence often takes place outside of the narrative, in the sense that narrative necessity does little to explain it. What this means is that while Marian's murder is certainly violent it is conceptually a part of the narrative, it is contained within the narrative, it is thus neutralized by the narrative (by this I mean it is made to serve its purpose and nothing more), and it is nothing without the narrative, nothing in the sense of taking the scene out of its context renders it meaningless. The scene of violence, looked at as mere juxtapositions of knife raised, woman screaming, knife raised, woman screaming, lacks clear communicative function. Something is

\footnotetext{
${ }^{7}$ Clover's argument is much more nuanced than this brief reference indicates. Her focus is on the dialectic of identification that takes place between audience and victim/victimizer in horror films, resulting in crossgender identifications with gendered subject positions that signify particular location within violent economy of the film; for example, victimizers are often male, yet obviously gendered as feminine (Norman Bates is archetypal in this respect), resulting in an identification with a feminine-male killer subject position. Alternately, Clover argues, the survivor is often a female that is gendered masculine, resulting in the masculine-female Final Girl subject position.
} 
happening, but in order to make sense of what it is gaps must be filled in (specifically the obvious gap of what takes place between "knife raised" and "woman screaming"); it is filling in these gaps, which occurs naturally and as a part of the experience of the film's narrative, that the scene's communicative function is fulfilled. There must be symbolic mediation of one kind or another, and within the film this symbolic mediation is via the narrative, in order for the images of Marian's death to have meaning. In Hostel, on the other hand, even within the film's narrative Josh's torture really makes no sense and if it is taken out of context, viewed merely as images of torture, its meaning (as I understand it) remains intact: a body is being unmade through violence.

In Psycho detaching the violence from the narrative disables the efficacy of the of the scene to communicate-signification, therefore symbolization, is essential to the quality of the modern cinematic horror film. The image of violence has meaning only in relation to narrative, which is to say symbolization. Resisting symbolization nullifies communicative coherence. In Hostel on the other hand the violence detaches meaningfully from the film's narrative, receptive to various interpretations. This is due in large part to the communicative weight carried by the careful representation of the scene of violence, incorporating all the visual elements towards that one end of expressing a situation of a hyper-real embodied-ness via a medium of disembodied influence. The image of violence frees itself from narrative, escapes the confines of symbolization, in order to take meaning with it into other domains of experience.

Having isolated the spectacle of violence in torture porn horror films, I now want to argue that it reflects a frustration with the inadequacy of contemporary subjectivity. 
This frustration has led to horror films in which violence is central to the cinematic experience, yet not contained by the film's narrative, therefore enabling it to have an effect of undermining subjectivity, subverting and annihilating it. This annihilation of subjectivity begins with the elimination of identity. This is a consequence of the violent act's power to affect subjectivity at its core, deeper than mere identity, on the body. The dehumanization inherent in violence stems from its ability to cut, so to speak, straight to the heart of a particular human being, into the body of the subject, to make obsolete all the identifying differences between one human being and another, to render one and the other equal in terms written upon the body of the subject, terms of suffering, pain, fear and death.

I insist upon contemporary subjectivity to emphasize the constructed-ness of subjectivity, a condition that is inevitably socio-historically contingent. This frustration with subjectivity's inadequacy stems from the failure of the modern subject to realize a world in which it can be globally prosperous; despite all the technological innovation of the previous two hundred years, innovations in agriculture, industry, medicine, and meeting the necessities of life, the same period has been marked by world war, genocide, and the threat of global annihilation. Terror and murder characterize the modern era; the dreams of the Enlightenment choked on the smoke of concentration camp furnaces. There is both conscious and unconscious frustration with the condition of the modern subject. I have decided to focus upon the latter, especially the manner in which this has been expressed in aesthetic cultural productions, such as the horror film. In my view the increasing graphic representations of violence in horror films, as well as the turn towards 
torture as the means of this violence, since the 1960's is indicative of an unconscious gesture towards dismantling subjectivity as a first step towards imagining some new form of social life.

Torture, as Scarry argues, is primarily about the "unmaking" of a victim's subjectivity. She writes, "the created world of thought and feeling, all the psychological and mental content that constitutes both one's self and one's world, and that gives rise to and is in turn made possible by language, ceases to exist" (30). This function of torture, along with the inverted mirror stage effect, a process of disintegration facilitated by the peculiar dislocation of audience identification that takes place in these films, makes contemporary horror films potential subjectivity subverting machines, anti-technologies of subjectivity. 


\section{THE SUTURE AND ABYSS}

A major tenet in the psychoanalytically influenced film theory of the previous thirty years is that audiences identify in various ways with the film image; Laura Mulvey's "Visual Pleasure and Narrative Cinema" is one example of a text from this tradition, a highly influential one. Mulvey recognized the Imaginary at work in cinematic experience: “ $\ldots$ it is an image that constitutes the matrix of the imaginary, of recognition/mis-recognition and identification, and hence of the first articulation of the $\mathrm{I}$, of subjectivity" (61). She goes on to link "fascination with looking" with the "initial inklings of self-awareness" (61). For Mulvey there is a clear connection between the visual, identification with an image, subjectivity, and cinema. She explicitly couples her discussion of audience identification with an explication of the mirror stage, "[t]he cinema satisfies a primordial wish for pleasurable looking, but it also goes further, developing scopophilia in its narcissistic aspect" (61). The cinematic screen and the mirror are similar, she goes on to say, in that both are involved in "framing... the human form in its surroundings," and concludes "the cinema has structures of fascination strong 
enough to allow temporary loss of the ego while simultaneously reinforcing it... [this] forgetting the world as the ego has come to perceive it (I forgot who I am and where I was) is nostalgically reminiscent of that pre-subjective moment of image recognition [taking place in the mirror stage]" (62).

Of course, Mulvey's major point in that essay is to elaborate upon the two forms of identification she discerns in the cinematic experience, the scopophilic and narcissistic. However, it is significant that in her discussion of audience identification she invokes Jacques Lacan's mirror stage. Mulvey seems to suggest that an identification similar to the one that precedes subjectivity takes place in cinematic experience; the image occupies a position in relation to the audience that brings it into contact with the audience's most basic psychic tendencies. The image is either an object of desire (scopophilia) or an object of narcissistic identification.

Narcissistic identification would be an apt name for the identification Lacan described taking place during the mirror stage. Indeed, during the mirror stage identification, the assumption of the specular image has to be considered the highest possible fulfillment of the narcissistic desire: the self literally becomes the image, an absolute merger of identity and image, or, even better, identity (which in my view is always an after-effect of subjectivity) only becomes possible by the complete immersion in the image. Of course this is what Mulvey is getting at in claiming that the cinema develops "scopophilia in its narcissistic aspect"; the object of desire becomes an image of one's self, the image of one's self. 
Mulvey is not the only film theorist to describe identification as integral to the cinematic experience. Kaja Silverman, for instance, has also examined the dynamics of audience identification, specifically as it is related to an operation undertaken by audiences in order to organize the cinematic experience into a meaningful one, an operation she has called a suture ${ }^{8}$. Suture is "the work involved in cinematic identifications," according to Judith Halberstam, who discusses Silverman at length. She explains:

Silverman uses 'suture' to identify the relationship between lack or loss [terms familiar from Lacan's theory of the subject] and subjectivity within the activity of spectatorship. Because there is always something we are denied access to upon the screen, always a perspective that cannot be rendered, a shot that reveals only the limitations of vision, then, she argues, it is lack that structures our relation to cinematic knowledge. (153)

Identification describes the audience relationship with the cinematic image; the same term describes the relationship between infant animal being (the pre-subjective human object) and the mirror image upon which subjectivity is subsequently erected. The identification takes the form of a suture, an operation of organizing cinematic experience-essentially fragmented and incomplete, imagine for instance the various "shots" that make up any cinematic scene-into a meaningful whole.

Think again of the shower scene. Many film critics have commented upon the frenetic rapid fire editing of that most famous of death scenes, and in examining it (in slow motion no less) I pointed out that there is only one brief image of Norman's knife actually touching Marian's body. The image, not quite merely a flicker, occurs is less

\footnotetext{
${ }^{8}$ Silverman in fact borrows these term from Lacanian psychoanalysis, especially the work of Jacques Alain Miller.
} 
than a second watching the film at normal speed and it seems motivated more by some perverse sexual symbolism than by any real attempt at representing a violent knife attack (only the tip of the knife is seen piercing the skin a few inches below her belly button, immediately following this image is Marian's breathy "Oh!"). I'm not sure what Hitchcock intended with the image, but I'm rather fairly certain he did not intend it to bear the full burden of visually representing Marian Crane's murder. No, that task is up to the audience and is accomplished via the symbolic mediation of the scene; placing it in some narrative, filling in the gaps between images (knife raised, Marian screams, repeat), making sense of what is seen.

In other words, by performing a suture.

Of course, in Josh's torture scene, the audience is made to adopt a point of view I described as analogous to third person limited narration, seeing things from neither character's perspective but also not seeing everything that happens. Suturing is necessary here also, in order to fit the scene within the film's narrative. The difference in the two scenes, and the suturing that takes place in them, is that in Psycho the specific violence of the scene is a part of the suture, that is to say it is provided through the audience's symbolic mediation. It is not seen. Hostel, on the other hand, displays little but the violence of torture, via its images of the instruments, of the torturer (as ultimate instrument), of the abattoir (the scene of the torture), and finally through its graphic depiction of the physical violence upon Josh's body—-the drill driving into his thigh (followed by the shot of the drill dropped back on the table top, tangled chunks of bloody flesh wrapped round it). It is in attaching these scenes of violent torture to the film's 
narrative that the suture takes place; the violence is seen. Of course, my point is to detach the scenes of violence from the narrative--it is the fact that one can do that and retain meaningfulness that separates Josh's torture scene, and much of the violence in contemporary horror films, from the type of violence represented in classic horror films.

Elaine Scarry, you will recall, described torture's primary purpose as one of "unmaking" its victim, which I understand (from her attention to the role of language in determining one's selfhood) as unmaking the victim's subjectivity. It is this function of torture that I want to emphasize alongside the analogy of audience-film identification and mirror stage identification. If the latter is about the making of a subject through identification with an image of a stable, whole body then is the former not potentially about reversing that identification? In a violent image from a horror film, especially one in which torture is taking place, the audience is forced to identify with an image of a stable body coming undone, coming apart, going to pieces. While in the Symbolic register the experience of such a scene varies, due to the subordination of the visual aspect to the law of symbolization, I suggest that in the Imaginary register the experience is consistently one of disintegration. Detaching the scene from the narrative, analyzing the scene as pure visual image is key for recognizing this experience, although it is not essential for the effect of the experience.

And what is the effect of this?

A crack in the foundation of human being, so to speak. Subjectivity constructed upon an identification; subjectivity dismantled via identification. The mirror stage in 
reverse. Lacan's mirror shattered, the image of the stable body splintering, what was whole becoming many.

And what is left for the subject?

The abyss behind the screen. The inevitable nothing behind the projections, images, identifications. The black hole from which signification cannot escape, the void of the Symbolic. A void into which the law of symbolization falls, unravels, loses itself entirely. Not pure void, not nothingness in an ontological sense, just the nothingness outside the Symbolic. In a sense, this is the void of the Real. Shattering the mirror is shattering one wall of the Symbolic, opening of a new frontier. If the Symbolic is the domain in which "human" being takes place, subjectivity as such is constructed, and if this domain is clearly partial in terms of human experience (as the need for other registers of experience-the Imaginary and the Real-attests it is), then by expanding upon this domain — not by extending the subordinating logic of the domain—but by expanding the domain of "human" being, the domain of subjectivity itself, to include aspects of subjectivity that have either been occluded from modern forms of subjectivity or discover new ones. Either way, the expansion of the possibilities of human being, subjectivity as such, seems possible.

But what is it that suspends audiences over this abyss, making them susceptible to its lure of emptiness, exposing them to its nothingness? Why can't the safety of a sutured identification attach audience psyches safely on one side or the other of this abyss of meaning, locating them in relative safety? The answer lies in a peculiar effect of audience dislocation. 


\section{THE MODEL}

Imagine a vertical line intersecting a horizontal plane. The scenes of graphic violence in contemporary, or postmodern, horror films can be understood as placing their victims on this vertical line in relation to the victimizers. The violence takes place with the victims in a subordinate position in relation to the victimizer. This subordination of the victim is characteristic of a fictional world whose ontology is radically Other in comparison to classic, or modern, horror films. This vertical line is a movement away from the normal space of modern horror, a descent into psychosis. Hostel is an exemplary postmodern horror film. The horizontal plane is the location of the violence in modern horror films. The cinematic example par excellence of modern horror is Psycho. The move from Psycho to Hostel is a shift from the horizontal plane to the vertical line.

Now, what does this spatial model, this way of representing the relationship of victim to victimizer, tell us about the fictional worlds in which this violence is taking place? This model provides a means of locating the victim in the ontology of the fictional world, a means of understanding what the victim's relationship is to the perpetrators of that violence. And in what way does that relationship bear upon the victim's situation in that fictional world? By locating the victims, victimizer and violence on the horizontal 
plane of modern horror one locates the victim in an ostensibly equal relationship with the victimizer. Also, both victims and victimizer are grounded on a plane in which "normalcy" is a regulatory concept, defining the victimizer as an aberration. Thus this horizontal plane model of ontology, describing the fictional worlds of modern horror, represents an ontology in which horror appears aberrant, marginal, Other; ultimately this ontology is one in which a fully-fledged bourgeois ideology dominates. The world is normal, "we" define normal, and thus "we" define our world in our terms and that which does fit into our definition (so the thinking goes), must be deviant. Normalcy reigns, with both feet firmly planted on the horizontal plane.

This equality suggests ontology of normalcy and deviation; what I mean is that the victim is (reasonably) normal, and recognizes his or her world to be normal, but becomes aware-via the violence enacted by the victimizer-that deviation is the source of horror. The victimizer is an aberration, a deviation, an Other not only to the victim but also to the very ontology of the fictional world. An even better formulation of this idea is to say that while a normal fictional world necessarily needs deviation in order to define its normalcy, the deviation must occupy a place of Otherness. The deviation must not be the norm, but rather must be that which gives the norm its meaning by its difference. Furthermore, the deviation must be contained within the norm, thus the horizontal plane as model of this type of ontology: a fixed field of normalcy, with its Other existing in scattered pockets within it. Normal and deviant mutually dependent upon each other yes, but not in such a way as to establish two equally matched spaces - a binary. Instead, 
deviation has to be de-centered, variously manifested, generally isolated and unconnected.

The victimizer is an aberration. And although normal is defined by contrast with abnormal, there is no reason intrinsic to the ontology of the normal fictional world that explains why the abnormality of the victimizer expresses itself as horror. The horror arises from the circumstances of the aberration. The monster, or victimizer, in modern horror films is aberrant in some specific manner that predisposes him, her, or it to horror. Dracula and Norman Bates cross over borders of normal but they do this because of who or what they are and not because the world in some manner makes this necessary.

Norman Bates is not normal. He is psycho. He embodies deviation in that he is a localized manifestation of deviance (and by that I mean specific to his own circumstances) and does not, or cannot, identify with normalcy. He and Marian occupy horizontal positions in relation to one another: he is a localized deviant on the stable and static plane upon which he and Marian move, he does not identify with normalcy (he may identify himself as normal, that is he may think there is nothing wrong or different about himself, but the audience knows better) while Marian does (or at least she does from the audience perspective). Again, it is worth pointing out how the normal ontological model reinforces pseudo-bourgeois notions of aberration as the source of horror, revealing modern horror as ultimately a socially conservative ideological apparatus.

Of course, from a Lacanian perspective psychosis names that condition of subjectivity that is absolutely Other to any other subjective state of affairs. Psychosis is deviation par excellence. In psychosis a subject is not really a subject in the same manner 
as other (neurotic) subjects; the Name of the Father, that Master Signifier grounding the subject's experience in the Symbolic, is absent, "foreclosed" is how Lacan describes it, resulting in a condition in which the psychotic is perpetually submerged in delusion and hallucination, in which meaning generates from no fixed point but is always shifting, proliferating, taking on new manifestations, always in motion. The psycho is the name of these scattered pockets of deviance peppering the normal landscape.

What is the situation of postmodern horror?

I described it as a vertical line, one intersecting the plane upon which modern horror takes place. Imagine this vertical line intersecting the horizontal plane of a normal fictional world precisely at the point where the victim exists, the line separating the victim from this normal world, plunging them, along with the victimizer ${ }^{9}$, into some other space not organized in the same manner as what has been called normal. Instead of a relationship taking place horizontally, in which the victim always has recourse to the fact of normalcy and recognizes the horror befalling him or her as an aberration, in this new space the only normalcy is the violent horror of the victimizer. Instead of moving in a homologous relationship to one another, as they did on the horizontal plane of modern horror, and which implies the victim could move away from the horror of the victimizer, in this new space, along this descending line, there is no where to go, no way to get away. Victim and victimizer are locked in an embrace of horrific violence. What is this space? This is the space of the psychotic. It is the unmediated experience of the psychotic. In postmodern horror the psychotic Other that was contained within the horizontal plane of

\footnotetext{
${ }^{9}$ Monster or psychopath, it all just depends on the film.
} 
normalcy breaks loose and submerges the victims in a world defined as a space of violence, madness, and horror.

It is significant that in many postmodern horror films, especially the torture porn variety, the violence often takes place in some specifically constructed locale, a place that's purpose is to be a site for horror. Now this is different from the older convention of the strange, unfamiliar place as site of horror (a convention dating all the way back to horror's roots in the literary Gothic: Walpole's The Castle of Otranto comes to mind). In modern horror, and even before, the strange setting was often used as a more or less transparent stand-in for the unconscious: labyrinthine dungeons, shadowy castles, dark and dangerous forests. These were places the victim undertook a journey to find, a metaphorical journey into his or her own mind, as it were, and once there, they confronted the horror and then returned. It is easy to see the Joseph Campbell-esque quality to this narrative structure. On the other hand, in postmodern horror, although the victims still (usually) have to undertake some journey to arrive at the site of horror they more often than not do not have to leave the world which they are familiar to get there. In other words, the horror takes place not in some exotic (and metaphorically meaningful) location but instead right in the most mundane places: an abandoned factory in Hostel, certainly reminiscent of an old castle, but much more relevant for the associations of ruined industry, failed enterprise, a crumbling edifice of modernity. It is indeed highly meaningful that the destruction of human beings takes place in this film at a site built for production-the dialectic of Enlightenment in a nutshell. 
The psychotic defines the ontology of this space; what was deviant is now the norm. A reversal has taken place. The very purpose of this space is to provide a setting for the violent horror enacted by the victimizer. The victim's relationship to the victimizer is now exactly opposite what it was in modern horror: in this new psychotic space it is the victimizer that establishes the norm, and the norm is to victimize, therefore the victim becomes the aberration. It doesn't take symbols to understand the relationship of victim and victimizer in this psychotic space, all it takes is an image of the violence that ensues; one reason why this model uses a vertical line, indicating a movement and not a static space, in order to describe the ontology of the psychotic world, is to emphasize that the worlds of postmodern horror are more or less merely staging grounds for the victim and victimizer relationship. The logic of absence and presence, which I understand as the logical basis of symbolization, establishes a concrete spatiality of defined spaces - thus the horizontal plane of modern horror, a Symbolic place. In lieu of that guarantee of definition, lost in the movement of postmodern horror, all that is left is flux, movement, proliferation of meaninglessness horror-thus a line. In other words, the static defined boundaries of the horizontal model are lost by this descent into an uncharted, undefined pure space of psychosis. There is no place for one to stand and get one's bearings; there is only the unending fall into violence.

This is not to lamely say that the fictional world is to blame for the victimizer's act—often enough, as in Psycho, it's an appeal to the world as ever-present external influence, as a set of conditions that is the excuse for the aberration that results in horror. No, to consider the ontology of the fictional worlds of postmodern horror as responsible 
for the horror is already to misunderstand that it is precisely this fictional world that is horror. There is no reason why. In this manner, at least potentially, postmodern horror has the capacity to be socially progressive ideological apparatus in that instead of reinforcing the notion that the world is normal, it puts that notion into question. Postmodern horror, again especially torture porn, displays a world in which the horror is as much a part of it as the victims and the victimizers, indeed more a part of it-horror is the rule.

Marian Crane inhabits identities indicating her subject position is somewhere other than the "traditional" female subjectivity of her time and place, and this of course does mean that, in a sense, she is not "normal," but this does not mean the world in which she exists is one without normalcy-it is normal, after all, to be a little different, to deviate from the norm in some small way; this is what is called being an individual. It is an entirely different thing indeed to wake up bound to a chair in a dirty room full of power tools. The difference is this: in the latter situation there is no recourse to meaning, logic, or authority in order to explain or escape impending doom. Josh wakes up in the abattoir; Josh dies. It is entirely "normal" that this takes place (the Surgeon has bought Josh, after all—what is more normal than disposing of one's property as one sees fit?); this death means nothing, it isn't the result of some action, some cause and effect sequence, nor can it really be considered a violation of either legal or moral codes. Notice how the police are involved with the torture cartel, and also how nice of a man the Surgeon is (when he's not operating without anesthesia): he's a family man, quick to offer advice and comforting words to a young man in trouble; that is until he gets Josh in the abattoir. 
Norman Bates' horror can be—in fact, it is—explained away, in this case by a representative authority on such matters, a psychiatrist. There is no such explanation for the Surgeon or any of the other clients in Hostel. They do what they do because they can, because they want to; that's reason enough. The pursuit of a personal end, whether it be pleasurable gratification, some ethical imperative or merely economic survival, is a cornerstone of post-Enlightenment thought ("life, liberty, and the pursuit of happiness"), one that merges well with the capitalist imprimatur. I don't think naïve equivalencies between torture porn and capitalism are appropriate, but it appears rather clear that under a different set of ideological conditions the problem of motive would remain, making postmodern horror, torture porn especially, difficult to imagine. I'm certainly not the first to draw conclusions linking capitalist ideology with violence and madness (Anti-Oedipus is of course a key text), but it might be in the realm of aesthetic cultural productions that such affinities may be most markedly pronounced, most visible.

Furthermore, and more importantly, this shift from normal to psychotic, from the horizontal plane to the vertical line, is a dislocating and disorienting one for the audience, resulting in a mode of identification that doesn't allow for the audience to settle on one object or another (the victim or the victimizer), leading to short-circuiting of the identification process. The modes of viewing with which audiences are most familiar, modes based on audience identification with the cinematic apparatus, are inadequate for the experience of postmodern horror films. What ends up happening is the collapse of symbolizable identification, that is to say identification along the lines of Mulvey's model, resulting in an experience of what earlier I called the abyss: the audience 
continues to identify with the cinematic image, but no longer in the Symbolic register, which has fallen away, forming the abyss around which the suture continues to take place. The audience sees the image but has no symbolic mediation available to makes sense of it. The identification takes place solely in the Imaginary.

Whereas in a modern horror film the audience may identify with Marian Crane in either of the capacities described by Mulvey, scopophilic or narcissistic, or, as is more likely the case, in some combination of the two, this identification eventually contributes to the horror of the film in the rather obvious manner of the audience witnessing the object of identification murdered. In Psycho Marian's murder creates a sort of audience identification vacuum, at least momentarily. There are other objects of identification that emerge, but part of the Hitchcock's genius in the film is to uncomfortably locate the audience, again only for a moment, over an abyss of identification. It is in this moment over the abyss that I think identification continues to take place between audience and screen image, but just not in any recognizably symbolic manner.

What I mean is that while Mulvey's models of audience identification depend upon symbolic mediation - an object of desire must necessarily fit within a narrative of desire, which is, as is the case with any narrative, constituted in the Symbolic ${ }^{10}$-and therefore cease to operate without it (a scopophilic object ceases to be desired in lieu of a narrative of desire) identification, which is after all founded in an act of looking, continues unabated. Carol J. Clover recognized this, and for her, in the horror films she

\footnotetext{
${ }^{10}$ Moreover, desire itself is a result of entry into the Symbolic: the desire for the lost primordial object that jumpstarts a subject's experience of language.
} 
analyzes, audience identification takes place largely outside the symbolic, more or less in purely visual terms.

Identity is clearly a function of subject position for Clover, with the "killer" (her terminology) occupying an identity based upon his or her inter-subjective relationship to the other characters, an identity is established through the film's narrative (the identity of killer in a film about a killer) but it is via visual markers, or to say this another way, it is in the way the killer "looks" (both the killer's physical appearance and act of looking) that marks him or her as such. Clover describes the killer position as feminized male, and Norman Bates is clearly an example, but her own examples include, among others, Leatherface (the chainsaw as prosthetic phallus) and Buffalo Bill (the full-on transsexual). These examples are the same ones taken up by Judith Halberstam.

For her audience identification is also not limited to the channels established by the film's narrative; The Silence of the Lambs, for instance, uses various means to facilitate a sutured identification across several objects in the film, most notably FBI agent Clarice Starling, convicted psychopath Hannibal Lecter, and finally, transsexual serial murderer Buffalo Bill. In identifying with these various objects audiences are exposed to sometimes contradictory sets of characteristics: Starling is vulnerable "daughter" to Lecter's domineering "father," Lecter is "powerless" in his incarceration while Starling is in a position of power thanks to her official authority, Buffalo Bill is a deranged monster while Lecter is calm, cool and collected detective, and so on. The film plays with the shifting identities of its characters, explicitly constructing identity as an effect of inter-subjectivity. At some point it becomes less clear that the audience 
experiences various subject positions shuttling through multiple identities and not, on the contrary, a single subject position pulsating with wildly divergent identity-possibilities. For Halberstam new possibilities for subjectivity emerge in the sutured identification taking place in relation to these shifting subject positions, or rather in relation to the roiling void of fluid identities these positions have become. The relation between audience and cinematic image, at least in postmodern horror films, is, for her, one of surface and appearance. There is no depth, only the horror of a void covered by the thinnest of membranes: the screen or the skin, either way it is the surface upon which the audience gaze must settle, a surface that is anything but settled.

Her book is titled Skin Shows, and she explains the title in Chapter Seven, "Skinflick: Posthuman Gender in Johnathan Demme's Silence of the Lambs,":

Skin is at once the most fragile of boundaries and the most stable of signifiers; it is the site of entry for the vampire, the signifier of race for the nineteenth-century monster. Skin is precisely what does not fit; Frankenstein sutures his monster's ugly flesh together by binding it in a yellow skin, too tight and too thick. When, in the modern horror movie, terror rises to the surface, the surface itself becomes a complex web of pleasure and danger; the surface rises to the surface, the surface becomes Leatherface, becomes Demme's Buffalo Bill, and everything that rises must converge. (163)

The surface is the object of gaze. Many postmodern horror films, especially the torture porn films, revel in surface level grotesquerie; not too many of these films spend much time dwelling on the deeper effects of their violence, that is to say the emotional or psychological effects, except in the most glancing of ways (I'm thinking of the famous ending of Hooper's original Texas Chainsaw Massacre in which Sally begins to laugh hysterically as she escapes). Emotional depth of character in these films isn't required, 
and in fact it is surprising just how flat most characters in these films are; Josh in Hostel has a couple of moments in which some psychological depth is implied, but these scenes are constructed in such a way as to mark Josh as weird and self-obsessed, and not to build his character. It's just as well since he meets his grisly fate about halfway into the film. Paxton's characterization, on the other hand, comes through his actions and the one real attempt to establish emotional depth with him—his reminisce about a drowning girl—is so blatantly foreshadowing as to be almost laughable. The victims are superficially objects of scopophilic identification, although their flatness and inevitably grisly demise makes identification with them, in any other manner than visual identification, difficult.

Already it is clear that audience identification with victims in torture porn films is based upon a surface level identification, that is to say with a relationship of looking at these bodies before, during and after they are mutilated and killed. Furthermore, the situation of the victimizer, and the worlds in which these films take place, is such as to foreclose on audience identification in advance. The victimizer and the fictional world, as I have been explaining, can be described as pure movement into an un-defined (indefinable) space of psychosis, the absolute rupture with the Symbolic order and the law of symbolization, the law of absence and presence, an absolute difference of experience. The audience cannot fully identify with the victimizer as the latter exists outside the space of identification in which the audience finds itself. The psychotic resists all symbolization; it is via symbolic mediation, i.e. a narrative of desire, that scopophilic identification takes place. The victimizer then is left as an object of narcissistic 
identification. But this situation is problematic, too: audiences tend to resist identifying themselves with the psycho sadist victimizers.

As Clover demonstrated, simple equivalency of audience and victimizer is bluntly crude, missing the nuanced manner in which (mostly young male) audiences identify with cross-gendered subject positions displayed in horror films. This is to say that dismissing audiences of torture porn horror films as sadistic sorely misses the point. Identification takes place with both victim and victimizer (this is Clover and Halberstam's point); what happens in many recent horror films, however, is that in lacking any proper symbolic means of settling upon an object, or even settling upon a relationship between objects (which is how Clover and Halberstam finally describe identification: a relationship of identification oscillating between two objects of various signification), the audience's experience of identification must take place in the Imaginary. This is why the experience is analogous to the mirror stage.

This dislocation of audience is partially the result of the shift that has taken place over the years from Psycho to Hostel, the shift from one fictional world ontology to another, the move from the horizontal plane to the vertical line of psychosis. What is this shift? It is a change in cultural awareness, in the cultural perception of horror films. A transformation in the function of horror films, the social function, one that indicates an awareness on the one hand of a different set of expectations (on the part of audiences) and, on the other, a different set of needs. Horror films have begun to different kinds of cultural work.

Take Psycho for instance. 
It's clear that I interpret that film as taking place in some version of a normal world, a world not very different from the one in which I, as audience member, find myself in. The film is uncomfortable perhaps, but not likely to upset my confidence in the reality of the normal that I encounter everyday. But subsequently horror films began to migrate into far more unsettling fictional worlds.

Wood, in his description of apocalyptic horror films in the 1970's, is for the most part, describing films that take place in this new ontological space. Texas Chainsaw Massacre is one of Wood's primary examples; therefore it is fitting that the recent remakes of Tobe Hooper's early confrontation with late capitalism are exemplary of this most recent trend in horror, torture porn. It is in this manner that the shift in the genre, in the form, cinematic horror, can be best seen: the socio-historic circumstances of an emerging aesthetic cultural production provide the condition for particular content, which appears more or less latently beneath the manifest conventions of the genre at that moment. Whereas the original Texas Chainsaw Massacre was an art film masquerading as horror the more recent versions, Texas Chainsaw Massacre (2003) and Texas Chainsaw Massacre: The Beginning (2006), are more or less sadistic revels in the unmaking of bodies, young people torn apart on the implements of a carnivorous age. Psycho then does not inaugurate this shift. It is not until the end of the 1960's, and George Romero's Night of the Living Dead, that the shift began. From a monstercentric horror, which implies a normal world unfortunately inhabited by aberrant monsters, to a diffuse, generalized and de-centered horror, in which the monsters are no longer aberrations, this is the arc of contemporary horror films. Night of the Living Dead 
invites its audience to locate its horror not so much in the monsters but in the world in which such monsters may exist. For example, the zombie epidemic is never explained. There is no answer for why the dead rise and feed on the living; moreover, it is significant that motive or cause is not even an issue in the film. Although the question is raised-apparently more from the pressing need of verisimilitude than from any earnest gesture at explanation—Night of the Living Dead proceeds just fine without answers.

What is most interesting about the film, and perhaps the reason for its immediate critical success $^{11}$, is that the group's demise is less due to the zombies than their own inability to cooperate. If the zombies are the world, in the sense of representing a psychotic, victimizing world, hostile and on the attack, beating down the door, then the fate of the group is clearly a precursor to that which befalls victims in today's horror films—-the ontologically psychotic world cannot be overcome, there is no escape, and not even one's best efforts are enough. Even Ben, the sole survivor of the zombie carnage, ends up dead.

The nihilism of Night of the Living Dead was taken up and amplified in the following years. Low budget horror films flourished. Many filmmakers set out to make films that were shocking or controversial, and often violence was the means of achieving that result. At the same time, many of these same filmmakers were inspired by Romero and consciously set out to make politically meaningful films. This was the era of horror films celebrated by Robin Wood in his "Introduction to the American Horror Film." Several films by Wes Craven, especially his work in the 1970's, are exemplary of the

\footnotetext{
${ }^{11}$ Immediate critical success overseas, I should say. The film was a sensational hit in Europe, while domestically, at first at least, it was merely a sensation.
} 
kind of horror that was being spawned then: Last House on the Left (1972) and The Hills Have Eyes (1977) are two films in which brutality, both in terms of the on-screen violence and the nihilism of the film's narrative, far exceed previous films. Craven's recurring motif of the violence within normal people—the grief-stricken parents of Last House, for example—is a means of representing one of my basic premises: violence has the capacity for subjective transformation. In fact, a later Craven film, 1984's A Nightmare on Elm Street, explicitly links subject position and identity with graphic violence $^{12}$.

It is not possible to painstakingly chart the shift in horror films from the modern model of normality, on the one hand, the horizontal space of horror in which the victimizer represents an aberration, best represented by Psycho and, on the other, the postmodern model of psychosis, the vertical descent of victims into the psycho world of violence, represented in this essay by Hostel. I have only elaborated upon this distinction in order to explain the dislocated audience experience of identification in postmodern horror, an experience that contributes to these films' subversive potential.

I have been describing a model of thinking about horror films that allows for a distinction between the fictional worlds of Psycho and Hostel. The distinction is one of ontology, a difference in the kind of being in these fictional worlds. The purpose of this distinction is to demonstrate another basic difference in the modern and postmodern

\footnotetext{
${ }^{12}$ For instance, when one young victim asks the film's supernatural villain, Freddy Krueger, who he is instead of answering, or even speaking at all, Krueger deliberately (and in medium close-up) cuts off a pair of his fingers. His name, it appears, is less a marker of who he is than the simple fact of violence. It is also significant that supernatural monster Freddy Krueger is "created," so to speak, in the film via violence-he had been, in life, a child molester who met a violent end at the hands of angry parents. Only through violence could the character of the film come into existence.
} 
varieties of horror film, which, in my view, is the difference between, on one hand, an audience's capacity to identify with the victims, to recognize some version of the world in which they - the audience-imagine themselves to live, a normal world in which aberration is the source of horror and, on the other hand, the foreclosure of that capacity. The psychotic world of postmodern horror dislocates the audience, does not allow identification (at least not in the same way as modern horror did), and, in the particular genre of postmodern horror best represented by Hostel, torture porn, the film actually demonstrates to the audience that the locus of subjectivity, the body itself, is nothing but a fragile vulnerability waiting to be undone. The violent image of torture is a potent one when one considers to what extent subjectivity relies upon the Imaginary identification with an external body. The dislocation of audience identification creates the condition in which the transference of a new subjectivity is possible by not allowing for identification to take place in a "safe," symbolically mediated manner, but instead forcing identification to take place in an entirely different register.

I am arguing that fictional representations of violence, such as those depicted in horror films, are subversive to subjectivity as it has been constructed in the advanced capitalist Western cultures. The subversion is the consequence of an at least three distinct things: the inverted mirror stage effect, the dislocation of audience identification, and the "unmaking" effect of torture.

This subversion begins with the audience experience of violence in these films, the visual experience of witnessing this violence as an image. The representation of violence in films—and not just in horror films—has become increasingly graphic since 
the 1960 's, becoming, somewhat paradoxically, both more realistic and impossibly garish. Certainly this trend towards more intense graphic representation of violence in films can be partially explained by advances in special effects technology and some sense of competitive one-upmanship on the part of film makers, as John McCarty argues in Splatter Movies. But I think this trend can also be explained by indicating an unconsciously perceived need to unsettle the Imaginary foundations of subjectivity, a sense that subjectivity is not adequate for the contemporary experience of the Real, that in some sense the models of subjectivity have in fact failed. The trend towards increasing graphic violence is a solicitation of new subjectivity. Robin Wood discusses how widespread feelings of a "generalized crisis in ideological confidence... habitually rendered, of course, in terms of personal drama and individual interaction, and not necessarily consciously registered" mark the American cinema of the 1970's, and it is my contention that realizing the inadequacy of subjectivity is a part of this crisis (Wood Hollywood 44, my emphasis).

The second part of this subversion is due to the inability for the audience to identify with the films, or more precisely with the contents of the films. The problem of closing a suture around always shifting objects that already dynamically resist identification is that the wound is never properly closed, the stitches can't pull the frayed ends of an audience psyche tight enough, the abyss behind the screen hangs open and waiting, always around the edges, menacing potential. Language fails in these persistent gaps. The image remains. The image always remains. Contemporary subjectivity, which is to say modern subjectivity, which is to say even more precisely say post- 
Enlightenment, post-Hegelian, advanced capitalist globally technologically mediated and connected subjectivity, the subjectivity of 2007, YouTube and 24-hour news networks, is, despite all of its accoutrements, essentially incapable of living for long in the world.

Late in life Freud wrote "Man has, as it were, become a kind of prosthetic God," an amplified human being more capable of situating him or herself in the world thanks to "advances in civilization" (738). Technology held the promise of transforming human being, but Freud was too much a thinker of his dark Victorian times to settle on whether such transformation would tend towards amelioration or annihilation. My model of subjectivity and identity is analogous to Freud's notion of human beings as prosthetic Gods: I imagine the human animal being donning a shell called subjectivity, necessary for any inter-subjective, that is to say social, experience; the shell is capable of accommodating more or less identities depending upon its process of construction, that is to say the subjectivation that has gone into its making. The subversion of subjectivity I have described is not, strictly speaking, destruction: there is no condition of nonsubjectivity. Instead the subversion functions as modification. Imagine a shell covered with electrical outlets; each outlet is where an identity plugs in. Some shells have more outlets than others, some have different kinds than others. Subversion of subjectivity means that the basic structure of this shell is affected in such a manner as to allow for a re-constitution that may result in increased capacity for identity. 


\section{THE SUBJECT}

I present a theory of subjectivity and identity that synthesizes Lacanian psychoanalytic theories of the subject with Foucault's concept of technologies of subjectivity, as these concepts have been taken up and modified by feminist scholars, such as Carol J. Clover, Barbara Creed, Judith Halberstam, and Linda Williams, working specifically with horror films. This synthesis will allow me to argue that subjectivity is the result of a process that is not fixed but is in fact dynamic and ongoing; any given subject's condition of subjectivity is determined not only by entry into the Symbolic register of experience, what Lacan described variously as submission to the law of symbolization, to the Name of the Father, or to the Master Signifier, but also by the continuing mediation of various technologies of subjectivity that operate throughout culture. It is this dynamism of subjectivity that allows for a re-imagining of the subject, once it is established how some of these technologies, in this case, the aesthetic technology of cinema, actually de-stabilize subjectivity and then, in conjunction with the very specific technology of the modern monster (as described by Halberstam) provide new alternatives. 
My understanding of subjectivity and identity corresponds to Gad Horowitz's description of basic and surplus repression. Drawing on Marcuse, Horowitz states:

Repression is also essential for the development of the human person, the selfconscious subject, and for the maintenance of culture-not only "bad," "repressive" culture, but any culture whatsoever, human culture as such.

Repression cannot be understood as an extraneous force which impinges on a preformed human nature and... either restrains... or perverts... [n]or is repression only an inherent flaw, an unavoidable weakness in human nature. The repression discovered by Freud is constitutive of human as distinguished from animal nature. (2)

He goes on to cite Althusser's claim that repression "transforms a small animal conceived by a man and a woman into a small human child" (Althusser, quoted in Horowitz 2). This is exactly the distinction I will make, referring to Lacan, in regards to subjectivity as a result of language.

Foucault argued that human beings are inevitably processed into normalized and productive social beings through various technologies of subjectivity, which he referred to as technologies of the self. Foucault deployed this idea in his various genealogical explorations of modern social practice. Judith Halberstam, my source for the terminology "technology of subjectivity," used Foucault's ideas in her study of Gothic fiction, modifying Carol J. Clover's approach to gender in horror films, in order to argue that the modern monster (her primary examples include Dracula, Leatherface, and Buffalo Bill) is an aesthetic technology capable of generating new, alternative versions of subjectivity.

For both Foucault and Halberstam, these technologies operate in specific cultural circumstances, and they can take on various forms. These processes are as various as the culture in which they appear. Some of the more obvious technologies of subjectivity can be found in education systems, religious institutions, and family structures as well as in 
other, more aesthetic cultural productions. These technologies operate both discursively and non-discursively. For Foucault, one very important technology was the rhetoric of the proper care of the self. It is Halberstam who takes this idea of technologies into the aesthetic domain, arguing first of all that the literary Gothic genre constituted one such technology, one generating alternative subject positions, and further that as the Gothic genre eventually lost its technological function it was taken up by the modern monster so that today it is the body of the monster that functions as a technology of alternative subjectivity. For her horror, being the natural domain of the modern monster, is rich with possibilities for changing the manner in which human beings experience themselves.

Theorists of horror have often stressed that the monster, in whatever guise it takes, is essentially a metaphor for otherness, and in fact one common method of reading horror has been to trace the vector's of a given monster's otherness through the sociohistoric matrix from which it emerged or within which it has gained particular currency. Wood, for instance, lists at least eight terms that could potentially be other in the horror films of the 1970's, including women, children, ethnic groups and the proletariat (Wood 169-170). Halberstam explains "The monster functions as monster... when it is able to condense as many fear-producing traits as possible into one body" (21). Furthermore, she describes the monster's "remarkably mobile, permeable, and infinitely interpretable body... is a machine that... produces meaning and can represent any horrible trait the reader feeds into the narrative" (21). The monster came to possess these remarkable function of multiplicity at the dawn of the $20^{\text {th }}$ century, indicating for Halberstam that the 
horror genre's ability to "take the imprint of any number of interpretations makes it a hideous offspring of capitalism itself" (3).

To restate the point in the terms of this essay, Halberstam describes the monster as occupying a subject position compatible with multiple identities, capable of becoming socialized in a variety of ways - the monster, in various circumstances, can be many things to many people. The monster is marked as such by a multiplicity due to its subjectivity being capable of supporting a wide variety of identity, a radical multiplicity. What this means is that the monster has the ability to generate horror in any number of situations precisely because as a subject it is not limited to a particular set of identitiesDracula, for instance, is "otherness itself... monster and man, feminine and powerful, parasitical and wealthy; he is repulsive and fascinating, he exerts the consummate gaze but he is scrutinized in all things, he lives forever but he can be killed" (Halberstam 88). It should be noted how her list of identities contains many contradictions: Dracula, for instance, is both immortal and vulnerable, all too capable of dying. Here is a subject that can be written in a variety of ways ${ }^{13}$, and not all of them add up to coherence and stability. The monster is therefore a model of alternative subjectivity.

Subjectivity establishes the possibilities of human social being; identity defines that social being. Although it is not my intention to catalogue the variety of processes of subjectivation, nor to even attempt the futile task of describing the multiple ways in which identities are formed, I do want to point out that since I understand subjectivation

\footnotetext{
${ }^{13}$ It is precisely this multiplicity that Halberstam describes as the characteristic distinction from earlier, Romantic Gothic fiction (Walpole, Radcliffe, and Lewis, for example) and modern horror fiction (Dracula is the exemplary modern horror fiction for Halberstam). As for my own distinctions with horror film, I use classic and modern interchangeably to denote films up to and including Psycho and continuing for some time afterwards while I use contemporary or postmodern to refer to films since 1985.
} 
to be a continuous process, it might seem difficult to distinguish between a process or technology that affects subjectivity and one that affects identity. Where does basic repression end and surplus repression begin? There are indeed two sets of processes at work here, and since some of the terminology of my sources differs from my own I must make some remark about this distinction.

Not all of what Foucault described as technologies of the self would be technologies of subjectivity to me; some would have to be technologies of identity. While dwelling too long upon this fine distinction of terminology would definitely lead us astray I think it is necessary to quickly acknowledge that I am indeed borrowing ideas and modifying them. Finally, as for deciding whether a technology is one of subjectivity or identity I have generally asked this question: is what is at stake some sense of the possibilities of human social being or is what is at stake merely one instance, one form, of social being? Answering the latter indicates a technology of identity.

Subjectivity is, in my view, that condition in which a human being must first enter in order to first of all recognize him or herself as a human being, to be recognized by others as such, and in order to assume identity. Identity is the prerequisite of social being, and subjectivity is the prerequisite of identity. Therefore subjectivity is first of all the condition in which a human social being must be made. I distinguish the pre-subjective human being as an animal being, a human object, while it is only after subjectivation that I think we can properly speak of human being, a human subject. A subject as such is like the blank pages of book, waiting to be filled with content. That content, that which specifically identifies a subject as such and such, is what constitutes a subject's identities. 
This content becomes the "I" of (inter)subjective discourse. The "I" is the specific identity (male or female, ethnic or racial, socio-economic class, etc) adopted in a specific situation by the subject. Subjectivity, analogous to the book in which blank pages are filled with identity-making content, is the locus of any given human being's identities.

As I conceive it subjectivity, although not the most basic of ontological categories, is the basic sociological category and as such is to be itself recognized as a social product ${ }^{14}$. I do not mean social product in the naive sense that specific individuals are products of their social experience, but instead in the twofold sense that subjectivity as such is a consequence of the social idea-it is necessary for social formation—and that subjectivity is produced by various social, or more precisely cultural, means. These means have been described as technologies in the sense that they are specific sets of techniques. These techniques function as guidelines for the self, establishing the subject as such in a condition in which identity is then possible. Deborah Cook explains, "the subject is... not pregiven, ... waiting to be discovered. When Foucault speaks of the formation of the subject, he means... the subject does not exist as a determinate form with specific qualities before the practices that make up the rappart a soi in different historical periods bring it into being" (Cook, quoted in Olssen 31).

The need to separate subjectivity from identity is apparent. This distinction is necessary in order to discuss subjectivity within a psychoanalytic framework while not

\footnotetext{
14 The most basic ontological category would therefore be the fact of organic human being, a human being as a flesh and blood creature. This distinction between the organic human being and social human being recalls Heidegger's use of "earth' and 'world' as two distinct ontological categories (see "On the Origin of the Work of Art"). What this amounts to is a tri-partite division of human experience: the pre-subjective animal being, the subject, and finally the identity, each one superimposing upon the previous. I think we must begin with the biological facticity of the organism, before moving to the psychic pre-condition for social being and finally to the various manners in which humans manifest as such socially.
} 
ignoring the obvious effects of social processes that shape, guide, and create human beings. Identity is an effect of social order, a necessary fiction of sorts, contingent upon interest and ideology. Moreover, any single subject has multiple identities. Identity can always be plural, but not infinitely so; there are, so to speak, more or less blank pages in different subjects, and it is in this variety that difference in technologies of subjectivity may be assumed. All subjects are not created equally - just as there as differences in identity so too there are differences in subjectivity, differences in the kind of subject produced by the process of subjectivation. These differences indicate variety in the processes of subjectivation.

For example, a subject that is compatible with more than one sexual identity has probably undergone subjectivation through a different means, or has had a different experience of subjectivation, than a subject for whom a single sexual identity is imperative. Sexuality and subjectivity enjoy a special relationship which will become more clear later. Some processes are more influential - Mark Olssen claims that "through... [formal] education the dominant epistemological matrix is internalized" (Olssen 30). Other processes aren't available to everyone.

What this means is that while subjectivity involves one's reflexive awareness of self and others-it is a psychic phenomenon-identity is the form in which that subject becomes socialized. Identities exist as social performative acts ${ }^{15}$, while subjectivity is the initial condition that allows social experience to take place. Identities are made possible via subjectivity; furthermore, the content and multiplicity of identity derives from

\footnotetext{
${ }^{15}$ Even one's own self-identity since it too is still a relationship that draws upon social experience, i.e., one understands one's self in relation to one's inter-subjective relationships.
} 
subjectivity. Which is to say that the number of pages, and what can be written on those pages, varies and is dependent upon the specific processes of subjectivation.

The variety of processes of subjectivation are responsible for this variety in subjectivity. But this variety must not be imagined to be too great. After all, since subjectivity is the basic sociological category of being it follows that the subjects of a given time and place, a particular socio-historic moment in a given society, must share some traits that allow for them to coexist socially in the first place. Normalcy is the operative concept here. Foucault argued that the increasing technologies of self he uncovered in the various discourses of public and private health, mental health, sexuality, and other human sciences in the modern era were all bent on normalizing subjects to the needs of their contemporary social group. I understand normalization then to be activity in subjectivation that perpetuates homogenous subject traits of a given time and place. Normalization is therefore the basic process of reproducing a given social episteme. Normalcy is a social definition and not grounded in biological fact. Normalcy is a function of social necessity. Normalcy is ideology. Furthermore, it seems that constructing subjectivity along these lines can result in a problem of adequacy. If subjectivity is constructed upon specific socio-historic principles in service of particular ideological interests then it is possible, if not likely, that this type of subjectivity may not be adequately built to accommodate the subject in a world that is not entirely determined by the interests of that particular ideology.

In Psycho Marian's identities indicate some slippage between pre-feminist normalized subjectivity, which I take to be the "traditional" (which is to say defined 
exclusively in terms of patriarchy) female subject position, and some other kind of subjectivity, not quite feminist (perhaps proto-feminist?), characterized by her willingness to steal from her (male) boss and strike out on her own (the unaccompanied female traveler being a somewhat scandalous idea in the "traditional" view). Marian frequents motels. This fact of her character is a consequence of the plot, yes, but I think it also indicates an anti-domesticity in Marian; after all, what kind of space could be more anti-domestic than a motel room? It is a lodging that is not one's home, sheltering but not a place of dwelling, home-like but not home. In that way, the space of the motel is an uncanny one, in the literal sense of Freud's term. Marian seems not to have a home, in a sense. She seems at home, as it were, in uncanny spaces. Even more so she herself seems a bit uncanny. She's on the run, towards a new and better life, but of course its only death she finds out on the highway.

It might be rather obvious to point out Psycho's hostility toward Marian as an un"traditional" female subject, but consider how her un-"traditional"-ness marks her as uncanny. She seems the very picture of female subjectivity-an object of the male gaze, an object of male pleasure, a servant of male desire (think of the scene in which her boss' client flirts clumsily with her-its like an almost laughable sexual harassment training film!), and yet... yet she's not. Marian, like Norman, isn't exactly what she appears. Somewhere in her subjectivation new spaces opened up, blank pages were added, allowing Marian identities not possible for her flatly dull co-worker (it's striking how glazed over the co-worker seems in comparison to Marian). The film does not explore what may have caused Marian's subjective difference; it is too busy planning on 
destroying her because of it. By analyzing her character through the lens of my subjectivity and identity model and determining that Marian's identities betray a subjectivity different from "traditional," pre-feminist female subject positions, I can posit that Hitchcock's film is conservative in its drive to eradicate Marian. From a contemporary perspective it is easy to see the film's social politics as reactionary and dogmatic, in the sense that it ignores the fact that female subjectivity is already undergoing transformations that makes Marian's un-"traditional" identities possible, and that it tries to enforce a patriarchal code on this female subject who is apparently already escaping such a code. Psycho either demonstrates the incoherence of such a dominating patriarchy (thereby escaping the full brunt of being labeled conservative) or it articulates it; take your pick, depending upon how one understands the confusing of male and female subjectivity in Norman, the condition of his madness, determines how one will understand the film.

In Hostel the relationship of subjectivity and identity is even more pronounced. The film goes out of its way in establishing specific identities for its two American protagonists, Josh and Paxton. The audience first sees these two smoking pot in an Amsterdam hash house. Later they are trolling for sex in nightclubs, drinking, getting into fights, and just generally causing a ruckus. At one point people are raining bottles down on them. These identities are variations on stereotypes of young adult American male behavior, and Josh and Paxton are identified as basically crass and hedonistic, typical frat-brother-gone-wild kinds of guys, with little in the way of redeeming qualities about them. They are both cardboard cut-outs, with little other than one basic distinction—Josh 
is the dreamy writer working on his thesis while Paxton is in law school-that separates them as characters. That distinction, significantly delivered via dialogue (in a kind of pep talk from Paxton to Josh), is the means of describing these characters in terms of their subjectivity. In fact, one way of viewing the film is to take into account the manner in which various identities fit the two American characters. They are given differing subject positions, the writer and the attorney ${ }^{16}$, each with its own capacity for different identities. They are put in similar situations, in which they must take on various identities in order to survive, and it is quite instructive of the film's implicit political meaning to pay attention to which subject position fares better. The rest of the film, from that subjectivity-defining pep talk onward, can be read as mapping which of these subject positions is more likely to survive in this nightmarish fictional world.

It is in this manner that the film can be read as a smart revision of Bret Easton Ellis' American Psycho: in the latter, capitalism has created the monster that is Patrick Bateman, and the audience is invited inside Bateman's world in order to be shown just how normal (even ideal) of a capitalist he really is, Patrick is capitalism realized, while in Hostel capitalism has created the conditions in which one either fully inhabits the capitalist identity, which is still brutal and associated with a willingness to kill, or one perishes. In American Psycho Bateman is a cautionary example of pure capitalism. In Hostel one must become Bateman in order to survive.

Identity is clearly a choice in Hostel. Paxton understands the limitations of particular identities, or the manner in which particular identities work (or do not work) in

16 These two professions represent, in Hostel, the distinction between idealism and solipsism (this is a pairing made by the film), on the one hand, and rational worldly engagement on the other. I should point out as well that the film marks Paxton as definitively capitalist. 
particular social situations. At least he understands this far better than Josh. Paxton, as is revealed in his pep talk speech to Josh, is clearly aware that social situation is solely the relevant factor in determining identity; in effect, he tells Josh to pretend to be interested in partying with sexually available European women at the disco, to adopt an identity that will let him at least seem to be having fun. Negotiating the moment is Paxton's utmost concern, here as in other places in the film, and as such I think it is safe to describe that attention to the needs of the present as a component of his fundamentally capitalist subject position.

Furthermore, identity is explicitly linked with appearance. In the Amsterdam nightclub Paxton points out Josh's fanny pack faux pas: wearing the practical if unfashionable fanny pack identifies Josh as "gay," to use Paxton's terminology, and leads to a couple of young women dismissing the duo's come on. Identity is conflated with appearance even more explicitly during Paxton's escape from the abattoir. After a particularly harrowing escape from his torturer (involving a ball gag, chainsaw, and severed fingers), Paxton must decide how to disguise himself so he can escape from the abattoir compound ${ }^{17}$. First he dresses in the garb of a torturer, donning a full length leather apron, long gloves, and a bizarre, quasi-medieval horned mask. Clearly Paxton is using appearance, specifically his clothes, as a means of inhabiting an identity. But this identity doesn't work for him, it doesn't fit. This is an identity that he cannot take on. He quickly changes out of it.

17 Which is in, as the audience has finally found out, housed in an abandoned factory complex. 
After a sequence in which Paxton descends to the compound's lower level—the furnace room in which the remains of victims are incinerated-he finally finds his way (how convenient!) into the room in which the torturers change clothes. It is here, in this room and in this scene, that Hostel reaches it critical apex in the confrontation between Paxton and another American, this one a client. Paxton has already donned a suit he found hanging in an unlocked locker, so when the other American comes in (he has just changed out of his regular clothes and wears the de rigueur apron of the torturers) he thinks Paxton is someone like him, which is to say a successful (and rich) businessman. The clothes make the man, in this case. It is significant that it is only after Paxton sheds the garb of a college boy on Bacchanalia and dons the attire of a businessman, that is to say the attire of a capitalist, that is when he is able to escape. But he not only escapes, he wreaks vengeance, killing not only the other American client but also the young women responsible for luring him to the agency, the guy back in Amsterdam who first suggested he and Josh travel to Slovakia (that guy just happens to have arrived in Slovakia and is hanging out in the street with the young women when Paxton comes driving up-talk about bad luck!), and finally, the man from the train, the Surgeon.

It is this last killing in which Paxton fully assumes his identity as capitalist: presenting the torture cartel's business card first of all, "Look, I have one too," he seems to be saying, before taking a razor blade to him. This is the film's key murder, the one in which Paxton gets his hands dirty (oddly enough, despite all the blood, Paxton's suit looks immaculate when he's finished), the one in which Paxton fully inhabits the capitalist identity required in order to survive—-this is what I referred to earlier as the 
necessity of becoming Patrick Bateman. Paxton kills because he has to, but it is clear from the staging of this last murder, that there is pleasure involved in killing. Whether this is the pure pleasure of capitalist violence or merely revenge the film leaves unanswered.

In Psycho the audience has Marian and Norman as their viewing objects: classic victim and victimizer. In Hostel there's Josh and the Surgeon. This relationship is more problematic than the other. First of all Josh recognizes the Surgeon as the man on the train to Slovakia, the eccentric who ate his salad with his trembling fingers, explaining he liked to have a close relationship with his food. He had laid his hand on Josh's thigh at one point in the conversation (they were side by side on the train seat) and Josh freaked out, erupting in an exaggerated bravado of homophobic retaliation. At that point the man retreated, leaving Josh to fend off the ridicule of his companions. But then, later in the film, once Josh is in the midst of his faux-existential angst over the lost girlfriend he runs into the man at the nightclub, at which point he insists on buying the man a drink and sitting with him, ignoring the uber hot Euro-babe who's lured him to the nightclub just to drug him for the torture cartel. Josh so fully enacts the reconciliatory male identity in this scene that he actually re-enacts the initial gesture of contact, reaching out and touching the man's thigh, a gesture met with an unreadable gaze, a shadow of madness that will fall across the man's face the next time Josh sees him, which is in the dungeon abattoir. He's bewildered, of course, when he wakes up later in the abattoir with the man, but there is also a moment in which he seems to entertain the possibility that this is in fact some strange homosexual tryst, and that his earlier eruption of homophobia was in fact 
warranted. This moment passes quickly. There is quite a bit of homosexual tension, latent homosexuality Freud might have said, at work in Josh. Of course, the older man-younger man dynamic, made especially clear during the nightclub scene in which Josh is counseled by the man, parallels a father-son or even teacher-student relationship but I think the manner in which the film emphasizes physical contact between the two of them, and the transgressive-ness of this contact, it is the homosexual relation that is ultimately most stressed. And its worth mentioning that yes, it's the same thigh initially touched by the man on the train that is pierced by the drill.

In Hostel sex and violence do not co-exist in the way in which they do in Psycho. Recognition, a basic component of sexual experience, is denied Marian Crane during her death scene; her experience is one of death and only death, regardless of the meaning of the act for Norman. She has no way of knowing her killer is a man sexually aroused by her. In fact, from her point of view, she is killed by a mad woman. Josh, on the other hand, recognizes his killer. The Surgeon removes his mask, becoming the man from the train, the man from the night club, the man who may have been a father figure, a teacher, even a one night stand. In Psycho violence replaces sex. In Hostel sex and violence mutually exist, mere pleasures, preferable only due to a matter of taste.

I have provided a relatively clear picture of my understanding of subjectivity and identity up to this point, stressing how subjectivity is a condition of self-awareness that is not static and given but is itself subject to the influence of various processes of subjectivation operating in culture with the purpose of producing the most normal, which is to say socially functional and productive, subjects possible. I have also described my 
understanding of subjectivity as stemming from a psychoanalytic perspective. It is now time to explain that perspective more fully. 


\section{PSYCHOANALYSIS: THE INVERTED MIRROR STAGE EFFECT}

Jacques Lacan elevates irregularity into an inevitably central position in any act of thinking culture. His lesson is that an aporia does not signal the end of thought, a limit, but instead a location from which one must veer away from one course and into a new course of thinking. Those tricks of consciousness that seek to assure the thinking individual that to think is to be, cogito ergo sum, here is where Lacan turned his scorn and it is here that he spoke his lesson. Irregularity must be thought as regular, the inescapable strangeness of experience mediated into meaningfulness cannot be effaced, it is in investigating how regularity and meaning come to be draped over what is essentially without either that the pitfalls of purely rational thought are most dangerous. What must be thought is the regular irregular. Lacan does not instruct one to attempt the act of thinking the paradox, or, to formulate this in even better terms, Lacan's lesson is not one of refusing the Siren-call of knowledge, it is one of refusing to succumb to the impossible urge to "think the paradox," the lure of the rational, refusing to even try and make a gesture of futile ratiocination. Abandoning the ship of fools called rationality to founder upon the rocks, Lacan veered off onto his on course, the sweet song of the Siren knowledge a symphonic soundtrack of apocalypse. Lacanian psychoanalysis is methodologically negative capability institutionalized; anti-institution par excellence, and 
as such seems to be the discourse most appropriate to an investigation into the manner in which subjectivity, that most basic of rational categories, should come into question.

For Lacan language is the alpha and omega of subjectivity. Language is how an animal being (the human object) becomes a human being (a subject); it is significant that in one of Lacan's earliest (and most important) statements on subjectivity, "The Mirror Stage as Formative of the I Function," he emphasizes that the pre-subjective child is an infant, a word which of course stems from the root infans, meaning without language. Language is the domain in which the human is born. The distinction between animal being and human being recalls Althusser's claim regarding repression. To be human is to be a subject; to be a subject one must enter language.

Entering language is no empty turn of a phrase. For Lacan that is exactly what one does—enters language. Zizek, following Lacan, has explained "the very constitution of the subject" in terms of "its entry into the space of symbolization" (82). As we shall see more clearly, this spatial metaphor for language and symbolic experience is vital. Language is a domain that always precedes the subject, and far exceeds the subject's ability to grasp it. In other words language is a vast place in which the subject finds him or herself located, and which always eludes total comprehension, total mapping, and total understanding. A subject's experience of language is always partial, disjointed, local and meaningful only in terms of that particular's subject's experience much in the same way that one's experience of any vast geographic space is, at any particular moment, limited only to one's experience of their local position. This partial experience is inevitable. 
Lacan described this domain of language as the Symbolic register of experience. Subjectivity is an effect of a human being's location in the Symbolic. Lacan described three registers of human experience: the Symbolic, the Imaginary, and the Real. Lacan's three registers of experience are often difficult to describe, and Lacan himself continuously revised his own understanding of them. In as brief a manner as possible I can state that the Symbolic is the register of language, the Imaginary is the register of the visual image, and the Real is that which resists representation in either of the other two, or, as Lacan himself said, that which resists symbolization. It should be stressed at this point that human experience takes place in all three registers simultaneously, and the division into these registers represents an attempt to narrow one's analytical focus to specific aspects of experience; i.e., one cannot speak of purely symbolic experience, one can only choose to focus on the Symbolic at the expense of the other two registers. Lacan, late in his career, came to describe the relationship of these registers as that of a knot: three strands of experience inextricably bound together, overlapping and intertwining, incapable of being loosened much less of being separated, this was the figure Lacan called the Borromean knot.

Fredric Jameson explains Lacan understands of the process of subjectivation as "a determination of the subject by language-[which] is not to say linguistic determinism" (Jameson 92). Lacan, in his widely read "Seminar on The Purloined Letter" says quite simply, "that it is the symbolic order which is constitutive for the subject" (Ecrits 7). Subjectivation is always a limitation, a fitting of a human being into the Symbolic, into symbolization as such, and the fit is not always altogether comfortable. There is always 
more to the "subject" than mere subjectivity. The Symbolic always precedes the subject, but the "subject," as determined by the Symbolic, is not exhaustive of the human being out of which (of which?) it is constructed. This notion of the non-exhaustiveness of the Symbolic will come up again. It is on "the symbolic plane," as Lacan calls it later in Seminar III, that the subject exists as such, that identity is possible. On the symbolic plane human beings adopt the humanizing shell of subjectivity, attaching themselves in various ways to chains of signification at various points--Lacan called these pointes de capiton. The intersection of Symbolic, Imaginary and Real that human beings understand as conscious existence revolves around these quilting points, the place in which particular subjectivities are anchored in discourse. But, and it is clear from just has been said, subjectivity is only considered in terms of symbolic relations. What is it about the Symbolic register, characterized as it is by language, which is so important for the making of a "human" being, that is to say a subject?

It is the basic law of language, what Lacan defines as the law of symbolization. Meaning is a consequence of the law of symbolization. The law of symbolization can be described as a dialectical relationship of absence and presence, exemplified for Lacan in Freud's famous fort:da example from Beyond the Pleasure Principle. The signifier, the word, that basic unit of language, only functions in the absence of that which it names; the presence of the word always indicates the lack of the object, or, to say this another way, it is the absence that allows for some other presence in the first place. Again, lack as constitutive of any human experience. Or, as Lacan states in Seminar XI "Everything emerges from the structure of the signifier" (206). What this means is that subjectivity, or 
"everything" which makes one a human being, is a consequence of the law of symbolization, demonstrated by the structure of the signifier, the logic of absence and presence, the play of the signifier, the inevitable lack at the heart of every human being. But the Symbolic is only part of the story.

What about relations taking place outside the Symbolic? After all, when one considers one's self as a subject it is unlikely that one first of all thinks of language: grammar, syntax, or an especially meaningful signifier or two. No, it is far more likely that one thinks first of all of an image of a body, a material being, an image of one's physical form. Registers. One tends to thinks of one's self as an embodied presence. Lacan described three registers of experience, all of which were involved in any subjective experience whatsoever; recall the figure of the Borromean knot. This was Lacan's model for describing the relationship of the Symbolic, the Imaginary and the Real. The Symbolic defines subjectivity as such but the latter is not exclusively a symbolic affair. Human experience is inevitably a fabric stretched across all three The Real is that which resists symbolization, remains forever literally unspeakable, the Real is:

essentially that which resists symbolization and thus resists the dialectization characteristic of the symbolic order, in which one thing can be substituted for another. Not everything is fungible; certain things are not interchangeable for the simple reason they cannot be "signifierized." (Fink 92)

The Real is not the real world that is there before it is described by language; it is instead those aspects of that world that elude symbolization. The Real is what is there without symbols to mediate it into meaning. It can never be symbolized. 
The Imaginary, it must be understood, does not occur as a stage prior to the Symbolic. Nor is it, strictly speaking, some larger field of experience in which the Symbolic takes place. The relationship of the Symbolic to the Imaginary is the relationship of describing a sunset to seeing a sunset. In the Imaginary symbolization does not take place, and this absence of symbolization results in the absence of the logic of presence and absence that structures (that is the first logical step towards structure as such) the Symbolic. The Imaginary is the register of experience characterized by the plenitude of the spatio-visual relation, a kind of pure visual existence. The Imaginary is the realm of the image. Jameson describes the Imaginary "as a particular spatial configuration, whose bodies primarily entertain relationships of inside/outside with one another," which is to say various relationships of identity, which I understand to coincide with his term "inside," and difference, coincidental with "outside," in the sense of being separate (Jameson 87).

The logic of the imago, conditioned by a basic fact of identification, dominates the Imaginary. What this means is that in the Imaginary an image exists not in a "signifier-izable" form, but in a relationship of pure identity (that image and "I" are the same) and difference (that image and "I" are not the same), pure spatio-visual relationship. This logic is the one that implicates the Imaginary in subjectivation, via a developmental process Lacan labeled the mirror stage.

In his "Mirror Stage" essay Lacan describes how the infant's early experience with its own image "reveals both a libidinal dynamism... and an ontological structure of the human world" (76). Lacan goes on to say the mirror stage is "an identification, in the 
full sense analysis gives to the term; namely, the transformation that takes place... when he assumes an image," or, in other words, an identification with an image (of one's physical self) that then becomes the manner in which one understands one's physical self.

What am I? I'm that image in the mirror, that's me, in my limited entirety, the full measure of my fragile being. Lacan's mirror is that place where I find myself for the first time. This "jubilant assumption of his specular image" manifests "the symbolic matrix in which the $I$ is precipitated in a primordial form, prior to being objectified in the dialectic of identification with the other, and before language restores to it, in the universal, its function as subject" (76).

Long before the entry into the Symbolic register, the true emergence of the subject as Lacan conceptualizes it, a foundation is being laid, a foundation upon which the subject will be raised. The mirror is the figure for the beginning of what can properly be called the human being. Lacan is quite specific about this:

This form [the form with which the nascent subject identifies] would, moreover, have to be called the "ideal-I" [Lacan's rendering of Freud's Ideal Ich]... in the sense that it will also be the rootstock of secondary identifications, this latter term subsuming the libidinal normalization functions. But the important point is that this form situates the agency known as the ego, prior to its social determination, in a fictional direction that will forever remain irreducible for any single individual or, rather, that will only asymptotically approach the subject's becoming, no matter how successful the dialectical by which he must resolve, as $I$, his discordance with his own reality. (76)

Before this imaginary organization of the mental functioning into a single, coherent entity the animal being (human object) cannot be considered a human being (a subject). The mind, as it were, becomes attached to a body via the mirror stage, an act that is absolutely fundamental for the development of a consciousness capable of adopting subjectivity. 
Lacan's mirror is the means by which subjectivity, that "function of the subject," becomes possible (Ecrits 429 ).

So what then takes place in audience experiences of graphic violence in horror films? What is going on for an audience watching Josh's senseless mutilation, psychically speaking? What are they experiencing that has implications for their own subjectivity? The destruction of an image comparable with that which the subject has identified in its first step towards becoming a subject. This is what I have called the inverted mirror stage effect.

The visual identification essential to the mirror stage, therefore essential to the development of subjectivity, is inverted in the audience's experience of graphic violence. Instead of identifying in the Imaginary with a stable body, one that provides a static point of reference from which to extrapolate an understanding of one's own body, the grisly images of violence provide bodies shown as unstable, indeed volatile, and ultimately very fragile. Furthermore, the audience is put in an awkward position of identifying with these bodies as they are being destroyed.

It is apparent in Lacan's Borromean knot model that the Imaginary is as much a component of human experience as the Symbolic. Lacan, in other words, does not limit human experience in the Imaginary register to only a particular time, early childhood for instance. It is clear that the Symbolic is the experiential register in which most human experience occurs, but it seems equally clear that this is due not to some intrinsic advantage of the Symbolic but instead to the brute fact of language as the medium through which so much human experience is necessarily mediated. Why should the 
Imaginary identification crucial to subjectivity be limited only to a specific time during early development? Perhaps, instead, it is more the case that the imaginary identification becomes subjected to the law of symbolization that establishes the subject; that subjectivity, as a matter of course, subordinates the experiences taking place outside its domain. This would begin to provide an answer to the question of rationality's stranglehold on post-Enlightenment experience-the Symbolic rules experience with an iron hand, imposing the logic underlying its own existence upon any experience: absence and presence, lack and plenitude, death and life.

A means then of understanding this focus on torture, on the process of physically taking apart a body, is to see it as necessary; an end in and of itself. Whereas Marian's death in Psycho served various narrative purposes, Josh's torture, even when divorced from any context, any narrative, still has spectacular effect, that is to say the effect of subversive spectacle. Divorce Marian's death from narrative and one still has a harrowing cinematic sequence, one in which audiences would still understand that a violent murder is taking place. But in order to understand this the audience must consciously mediate the visual spectacle of the scene with their own symbolically determined concept of murder; in other words, they have to symbolically fill in the gaps in the visual spectacle. The shower scene does not show violence, it merely presents several images in quick succession that when symbolically mediated become a narrative of violence. When viewed in slow motion ${ }^{18}$, the scene loses its renowned power to shock: instead of a visceral experience the audience has to actively participate in making the narrative work,

${ }^{18}$ As Laura Mulvey describes in her account of Douglas Gordon's exhibit 24 Hour Psycho, during which the film was slowed down to $1 / 24$ th its running speed; Gordon was drawing attention to the relationship of the still image, the photograph, and the cinematic apparatus, the medium of film. 
to tie together the images, to make them make sense. The images must be submitted to symbolization. Josh's torture, on the other hand, requires no such symbolic mediation. In fact, the latter frustrates symbolic mediation by occurring so randomly, so haphazardly, without any sense. Josh's torture resists symbolization not as some Real existential component but due to its intrinsic Imaginary value: there is "meaning" in the image, one lost in describing what that meaning is. The image of Josh's torture is enough, in fact, recalling Scarry's emphasis on the visual aspect of the torture process, it is safe to say that the torture takes place entirely in an Imaginary ${ }^{19}$.

Fredric Jameson, in his lucid and nuanced analysis of these two Lacanian concepts (see "Imaginary and Symbolic in Lacan"), speaks of the impossible yet entirely necessary task of formulating the terms of an Imaginary analysis, a new hermeneutic deriving from an attention to the peculiarities of the Imaginary register. For Jameson, one means of escaping the jaws of purely rationalist thought—in his work more or less identified with the logic of capitalism—is to seek refuge outside the Symbolic, to try and draw insight from an experience of the Imaginary that, while it's true would nevertheless have to find itself expressed in language, still might result in some thought capable of countering the pure rationalism of the Symbolic. I understand this call for Imaginary analysis as a call to pay special attention to the manner in which purely visual experiences may operate in a manner counter to how they fit into the Symbolic.

\footnotetext{
19 "Entirely" is misleading; Josh's torture takes place in all three registers, like any other human experience, however, it is meaningful via the Imaginary and resists the normalizing, rational meaningfulness of the Symbolic.
} 


\section{REFERENCES}

Edelstein, David. "Now Playing at Your Local Multiplex: Torture Porn," in New York Magazine. Feb 6, 2006. Accessed March 2, 2007.

$<$ http://nymag.com/movies/features/15622/>

Fink, Bruce. The Lacanian Subject. Princeton, NJ: Princeton UP, 1995.

Freud, Sigmund. The Freud Reader. Ed. Peter Gay. New York: Norton, 1995.

Halberstam, Judith. Skin Shows: Gothic Horror and the Technology of Monsters. Durham NC: Duke UP, 1995.

Horowitz, Gad. Repression - Basic and Surplus Repression in Psychoanalytic Theory: Freud, Reich, and Marcuse. Toronto: Toronto UP, 1977.

Jameson, Fredric. "Imaginary and Symbolic in Lacan," in The Ideologies of Theory, Vol. 1. Minneapolis: UP Minnesota, 1989.

Lacan, Jacques. Ecrits. Trans. by Bruce Fink. New York: Norton, 2007.

---. The Seminar of Jacques Lacan, Book III: The Psychoses. Trans. Russell Griggs. Ed. Jacques Alain Miller. New York: Norton, 1997.

---. The Seminar of Jacques Lacan, Book XI: The Four Fundamental Concepts of Psychoanalysis. Trans. Alan Sheridan. Ed. Jacques Alain Miller. New York: Norton, 1998.

Mulvey, Laura. "Visual Pleasure and Narrative Cinema," in Feminist Film Theory. Ed. by Sue Thornton. New York: NYUP, 1999.

Olssen, Mark. Michel Foucault: Materialism and Education. Critical Studies in Education and Culture. Ed. Henry A. Giroux. Westport CT: Bergin \& Garvey, 1999.

Phillips, Kendall R. Projected Fears: Horror Films and American Culture. Westport CT: Praeger, 2005. 
Scarry, Elaine. The Body in Pain. New York: Oxford UP, 1985.

Wood, Robin. "An Introduction to the American Horror Film." Planks of Reason: Essays on the Horror Film. Ed. Barry Keith Grant. Metuchen NJ: Scarecrow Press, 1984. 164-200.

---. Hollywood from Vietnam to Reagan... And Beyond. New York: Columbia UP, 2003.

Zizek, Slavoj. "Four Discourse, Four Subjects." Cogito and the Unconscious. Ed. Slavoj Zizek. Durham, NC: Duke UP, 1998. 74-113. 


\section{CURRICULUM VITAE}

NAME:

Christopher William Curry

ADDRESS:

2000 Unity Place, Apt. 802

Louisville, KY 40208

DOB:

Elizabethtown, Kentucky - June 17, 1973

EDUCATION

\& TRAINING: $\quad$ B.A., English

University of Louisville

$2003-2005$

M.A., English

University of Louisville

$2005-2007$

\section{INVITED PRESENTATIONS:}

K.P.A. Annual Meeting, March 2006.

Western Kentucky University

Bowling Green, Kentucky

"From the Backyard to BBQ: The Iconicity of the Chainsaw."

The Conference on Literature and Culture Since 1900, February 2007.

University of Louisville

Louisville, Kentucky

"Horror's (Anti) Technology of Subjectivity."

K.P.A. Annual Meeting, March 2007.

Union College

Barbourville, Kentucky

"Shattering Lacan's Mirror." 